\title{
Immobilization and Characterization of Purified Aspergillus flavus Peroxidase Mediated Silver Nanoparticle Synthesis: Peroxidase Surface Reactive Residues are Implemented for Reduction of Silver Ions, More than Its Active Sites
}

\section{El-Sayed ASA ${ }^{1 *}$, Rabie GH$^{1}$, El-Gazzar NS ${ }^{1}$ and Ali GS ${ }^{2 *}$}

${ }^{1}$ Botany and Microbiology Department, Faculty of Science, Zagazig University, Zagazig, 44519, Egypt

${ }^{2}$ Mid-Florida Research and Education Center, IFAS, Apopka, University of Florida, Florida, USA

\begin{abstract}
Silver nanoparticles (AgNPs) have been used extensively in various therapeutic applications, molecular diagnostics. Chemical methods for synthesis of AgNPs are frequently used, however, the expenses and releases of toxic byproducts are the main limitations. Biological methods provide an alternative source for AgNPs synthesis for its cost and environmental safety. Fungi possess unique system for $\mathrm{Ag}^{+}$resistance via secretion of multiple proteins for ions reduction to their nanoparticles. The objective of this study was to deciphered the mechanisms of $\mathrm{Ag}^{+}$reduction to $\mathrm{Ag}^{0}$ by $A$. flavus. The synthesized AgNPs by $A$. flavus have molecular size ranged from $9-15 \mathrm{~nm}$ with visual molecular stability for abundance of stabilizing agents. A. flavus peroxidase was purified, immobilized on chitosan, polyacrylamide and sodium alginate, and biochemically characterized with strong potency for $\mathrm{Ag}^{+}$reduction to AgNPs that are significantly stable $(-30.6 \mathrm{mv})$ and UV-Vis analysis $\left(\mathrm{A}_{390} \mathrm{~nm}\right)$. The immobilized peroxidase has a significant operative stability for continuous production of AgNPs with homogenous molecular stability till the $5^{\text {th }}$ catalytic cycle, emphasizing the efficiency of this technology for industrial scale synthesis of AgNPs. The reducing properties of peroxidase to $\mathrm{Ag}^{+}$to AgNPs is mainly due to the protein functional surface reactive groups than the enzyme functional active sites. Scalingup potency and molecular stability of AgNPs produced by immobilized peroxidase provides a new feasible technical avenue for AgNPs exploitation.
\end{abstract}

Keywords: Aspergillus flavus; Peroxidase immobilization; Silver nanoparticles synthesis

\section{Introduction}

Silver nanoparticles (AgNPs) containing compounds have been used in various pharmaceutical and biological applications as bactericidal agents, in formulation of dental resin, sanitizer sprays, respirators, socks, toothpastes, in addition to electronics and optics industries [1]. Physical and chemical methods depending on top-down and bottom-up approaches have been mainly used for production of AgNPs. The top-down method based on mechanical grinding of bulk metals to nano-size particles followed by addition of stabilizing agents [2], while the bottom-up technique includes reduction of metals, electrochemical and sonodecomposition [3]. Other methods were recently validated for AgNPs synthesis, including chemical reduction, electrostatic complexing with anionic surfactant aerosol with $\mathrm{NaHB}_{4}$, microwave-based methods, thermal decomposition and photoreduction [4-7]. However, the major problem for the physical and chemical methods are the extremely expenses, release of toxic byproducts, constrains significant environmental risks.

Microbial biosynthesis (green chemistry) of AgNPs being the most feasible, clean, eco-friendly technology to fulfil the huge requirements of AgNPs [8], in addition to their homogeneity on shapes, optical, electrical and chemical properties [9]. Microbial synthesis of nanoparticles has been studied extensively [10,11]. Metal ion reduction has been recognized as one of the heavy metal resistance mechanisms in microorganisms. Fungal biosynthesis of nanoparticles is usually initiated by trapping of the $\mathrm{Ag}^{+}$ions to the surface of fungal cells, subsequent reduction by surface enzymes, peptides and reducing compounds [12], in addition to secretion of capping agents to stabilize the synthesized nanoparticles. The reduction of metal ions to particles and their intra or extracellularly accumulation has been implemented as the basic mechanism for nanoparticles production in all microorganisms [13]. Biosynthesis of AgNPs in fungi has been attributed to various reducing enzymes, peptides, amino acids, sugars and organic acids [14]. The possibility of large-scale production of extracellular enzymes, economic viability and simplicity in handling are the distinctive advantages of using fungi in NPs synthesis. Amino acids of enzymes and proteins especially with free amino groups, thiols are mainly implanted with particles interaction, acting as reducing and stabilizing agents of synthesized AgNPs $[11,14]$. Various proteins as bovine serum albumin [15], glucosidase [16], trypsin [17], pepsin and laccase [18] are mainly involved in reduction of metals to their nanoparticles. It was claimed that enzymes and proteins that have free amino groups like phenylalanine, tyrosine, tryptophan and histidine and free thiol groups of cysteine are able to catalyse the reduction of metals $[19,20]$. Nitrate reductases as well as peroxidase had been

*Corresponding authors: Gul Shad Ali, Mid-Florida Research and Education Center, IFAS, Apopka, University of Florida, Florida, USA, Tel: (407) 410-6933 E-mail: gsali@ufl.edu

Ashraf SA El-Saye, Department of Botany and Microbiology, Faculty of Science, Zagazig University, Zagazig, 44519, Egypt, Tel: +201024686495; E-mail: ashrafsabry@zu.edu.eg

Received January 05, 2017; Accepted January 19, 2017; Published January 27 2017

Citation: El-Sayed ASA, Rabie GH, El-Gazzar NS, Ali GS (2017) Immobilization and Characterization of Purified Aspergillus flavus Peroxidase Mediated Silver Nanoparticle Synthesis: Peroxidase Surface Reactive Residues are Implemented for Reduction of Silver lons, More than Its Active Sites. J Nanomed Nanotechnol 8 : 420. doi: 10.4172/2157-7439.1000420

Copyright: ( 2017 El-Sayed ASA, et al. This is an open-access article distributed under the terms of the Creative Commons Attribution License, which permits unrestricted use, distribution, and reproduction in any medium, provided the original author and source are credited. 
Citation: El-Sayed ASA, Rabie GH, El-Gazzar NS, Ali GS (2017) Immobilization and Characterization of Purified Aspergillus flavus Peroxidase Mediated Silver Nanoparticle Synthesis: Peroxidase Surface Reactive Residues are Implemented for Reduction of Silver lons, More than Its Active Sites. J Nanomed Nanotechnol 8: 420. doi: 10.4172/2157-7439.1000420

remarked as potential enzymes/proteins, having abundant reactive amino and thiols groups that participate in metals reduction [21].

The objective of this study was to emphasis the potency of $A$. flavus for AgNPs synthesis. To purify and immobilize A. flavus peroxidase, comparatively kinetic characterization of the free and immobilized enzymes. To assess the operative stability of the immobilized peroxidases for bulk synthesis of AgNPs.

\section{Materials and Methods}

\section{Fungal isolates, identification, growth conditions and silver nanoparticles synthesis}

Fourteen fungal species were isolated from soils contaminated with wastes from Ceramics and Photographic Industries $\left(10^{\text {th }}\right.$ of Ramadan, El-Sharkia, Egypt). These fungal isolates were screened for their ability to reduce silver ions to silver nanoparticles according to Ahmad, Mukherjee [14] with minor modifications. Briefly, the fungal isolates were grown on liquid medium containing $0.7 \% \mathrm{KH}_{2} \mathrm{PO}_{4}, 0.2 \%$ $\mathrm{K}_{2} \mathrm{HPO}_{4}, 0.01 \% \mathrm{MgSO}_{4} .7 \mathrm{H}_{2} \mathrm{O}, 0.06 \%$ yeast extract and $2 \%$ glucose. The cultures were incubated for $28^{\circ} \mathrm{C}$ for 5 days then filtered and the collected mycelia were washed thoroughly with sterile distilled water to remove any particulate. The fungal mycelia $(10 \mathrm{gm})$ was suspended in $100 \mathrm{ml}$ sterile potassium phosphate buffer $(1 \mathrm{mM}, \mathrm{pH} 7.5)$ containing $1 \mathrm{mM}$ PMSF and $1 \mathrm{mM}$ EDTA, grinded thoroughly, the mixture was centrifuged at $6000 \mathrm{rpm}$ for $10 \mathrm{~min}$, the supernatant was used as the source of crude intracellular enzymes for synthesis of AgNPs. The crude extracts were amended with $1 \mathrm{mM} \mathrm{AgNO}$, incubated for $24 \mathrm{~h}$ at $25^{\circ} \mathrm{C}$, then the developed AgNPs was visually monitored from the intensity of yellow-brown color [14]. Distilled water supplemented with silver nitrate at the same conditions were used as control. The concentration and physical properties of the developed AgNPs were determined.

The recovered fungal isolates were identified based on morphological features [22,23]. The most potent fungal isolate producing AgNPs was molecularly identified based on the ITS sequences [24-26].

\section{Properties of silver nanoparticles}

The developed AgNPs was assessed by UV-Vis analysis using JASCO-V630 Spectrophotometer at $\lambda 200-600 \mathrm{~nm}$, normalizing to controls. The size of the developed AgNPs was determined using Zetasizer Nano S (ZEN 1600, Malvern, UK). The morphology and size of AgNPs were assessed by Transmission Electron Microscopy (TEM) (FP 5018/40, Tecnol G2 Spirit Bio TWIN) according to Ahmed et al. (2003). The presence of functional groups of amino acids as protecting agents to AgNPs was detected by Fourier Transform Infrared Spectroscopy (FTIR) (Thermo Nicolet model 6700 spectrum). The charge of silver nanoparticles was determined by Zeta potential analysis (ZEN 1600, Malvern, UK). Sterile distilled water with silver nitrate was used as negative control.

\section{Implementation of various coenzymes for induction of AgNPs synthesis}

The impact of NADH and pyridoxal 5 -phosphate (PLP) on the potency of A. flavus to reduce silver ions to AgNPs was assessed. Different concentrations of NADH and PLP (10-500 mM) was added to the fungal extract with $1 \mathrm{mM} \mathrm{AgNO}_{3}$. The mixture was incubated at $30^{\circ} \mathrm{C}$ for $24 \mathrm{~h}$, then the concentration and properties of the developed AgNPs was determined as described above.

\section{Peroxidase and alcoholic dehydrogenase activities}

The crude peroxidase activity was measured using $O$-dianisidine as substrate [27]. Briefly, the reaction contains $O$-dianisidine (50 $\mathrm{mM}), \mathrm{H}_{2} \mathrm{O}_{2}(0.5 \%)$ and $500 \mu \mathrm{l}$ of the crude enzyme extracts, in $1 \mathrm{ml}$ total volume. The reaction was incubated for $20 \mathrm{~min}$ at $37^{\circ} \mathrm{C}$, then the intensity of developed color was measured at $460 \mathrm{~nm}$. Blanks of enzyme and substrate were used separately. One activity unit of peroxidase was defined as the amount of enzyme oxidizing $1 \mu \mathrm{mol}$ of $O$-dianisidine per min under standard assay [28]. The activity of crude alcoholic dehydrogenase was determined (Vallee and Hoch, 1955). The protein concentration of the crude fungal extract was determined by Bradford assay [29] using bovine serum albumin as standard. The specific activity of peroxidase $(\mu \mathrm{mol} / \mathrm{mg}$ ) was expressed by its activity $(\mu \mathrm{mol} / \mathrm{ml})$ per protein concentration $(\mathrm{mg})$.

\section{Purification, molecular subunit structure and Zymogram analysis of $A$. flavus peroxidase}

The total crude protein was extracted from the mycelia of $A$. flavus by grinding in buffer containing EDTA and PMSF as described above. The crude peroxidase was fractionated by ammonium sulfate saturation $(20-70 \%)$, incubation at $4^{\circ} \mathrm{C}$ for $2 \mathrm{~h}$, then the mixture was centrifuged for $10 \mathrm{~min}$ at $4000 \mathrm{~g}$. The precipitated protein was collected in potassium phosphate buffer containing $1 \mathrm{mM}$ EDTA and dialyzed against the same buffer till complete removal of salt traces. The enzyme was purified by gel filtration chromatography using Sephadex $G_{100}$ and $G_{200}$ columns [26,30-32]. After column equilibration with the same buffer, the sample was loaded to the column and the enzyme fractions were eluted at flow rate $0.2 \mathrm{ml} / \mathrm{min}$. The activity of peroxidase and its protein were assayed by the standard assay.

The molecular homogeneity and subunit structure of the purified peroxidase were assessed using SDS-PAGE [33]. The protein sample (20 $\mu \mathrm{g})$ was boiled in dissociation buffer Tris- $\mathrm{HCl}(50 \mathrm{mM}, \mathrm{pH} 7.0), 1.0 \%$ glycerol, 2.0\% SDS, 5.0\% 2-mercaptoethanol and 0.1\% bromophenol blue. After gel running, staining with Coomassie brilliant blue R-250, the gel was decolorized with methanol-acetic acid and photographed. The molecular subunit structure was determined from the inference of authentic protein marker (PageRuler ${ }^{\mathrm{TM}}$ Plus, ThermoScientific).

Zymogram of peroxidase was analysed on native-PAGE (without SDS on gel and running buffer) [34]. After running, the gel was soaked on substrate solution $\left(10 \mathrm{mM} \mathrm{O}\right.$-diansidine, $1.6 \mathrm{mM} \mathrm{H}_{2} \mathrm{O}_{2}$ in $50 \mathrm{mM}$ succinate buffer of $\mathrm{pH} 5.5$ ). The gel was incubated for $1 \mathrm{~h}$ at $30^{\circ} \mathrm{C}$, the position of enzyme was allocated from the developed yellow color of oxidized $O$-diansidine, the gel was photographed by Digital Camera.

\section{Synthesis of AgNPs by the partially purified A. flavus peroxidase}

The potency of partially purified peroxidase to reduce silver nitrate to silver nanoparticles was assessed [21]. Peroxidase dissolved in potassium phosphate buffer was incubated with silver nitrate solution $(1 \mathrm{mM})$ for $1 \mathrm{~h}$ at $30^{\circ} \mathrm{C}$, distilled water with the same $\mathrm{AgNO}_{3}$ concentration was used as blank. The evolved yellow- brown colouring of the solution reveals the development of AgNPs. The synthesized AgNPs was collected by centrifugation at $5000 \mathrm{rpm}$ for $5 \mathrm{~min}$ and suspended in $10 \mathrm{ml}$ of sterile distilled water. The synthesized AgNPs were characterized by scanning UV-Vis analysis at 200-600 $\mathrm{nm}$ range. The morphology, aggregation, size and topography of the developed AgNPs were determined by TEM analysis. The size of the AgNPs was measured by the DLS analysis. 
Citation: El-Sayed ASA, Rabie GH, El-Gazzar NS, Ali GS (2017) Immobilization and Characterization of Purified Aspergillus flavus Peroxidase Mediated Silver Nanoparticle Synthesis: Peroxidase Surface Reactive Residues are Implemented for Reduction of Silver lons, More than Its Active Sites. J Nanomed Nanotechnol 8: 420. doi: 10.4172/2157-7439.1000420

Covalent and entrapment immobilization of the purified $A$. flavus peroxidase

To evaluate the potency of peroxidase for bulk synthesis of AgNPs, the enzyme was immobilized on different solid supports. The enzyme was covalently immobilized on chitosan [35] with slight modifications. Briefly, chitosan $(1.0 \mathrm{~g})$ was activated by soaking in $100 \mathrm{ml}$ of $0.1 \mathrm{~N} \mathrm{HCl}$ of $2.5 \%$ glutaraldehyde for $3 \mathrm{~h}$ at $30^{\circ} \mathrm{C}$, then neutralizing the mixture $\mathrm{pH}$ to 7.0 by $1 \mathrm{~N} \mathrm{NaOH}$. The mixture was centrifuged for $10 \mathrm{~min}$ at 5000 $\mathrm{rpm}$, the activated chitosan was washed with distilled water, collected and suspended in $10 \mathrm{ml}$ potassium phosphate buffer ( $\mathrm{pH}$ 7.0). The glutaraldehyde-activated chitosan has free reactive aldehyde groups that form Schiff base with the reactive amino groups of peroxidase[32]. One $\mathrm{ml}$ of peroxidase $(35.0 \mu \mathrm{mol} / \mathrm{mg})$ was added to the $5 \mathrm{ml}$ activated chitosan, incubated overnight at $4^{\circ} \mathrm{Cwith}$ gently shaking. The mixture was centrifuged and protein concentration of the supernatant was determined by the standard assay. The amount of conjugated protein with chitosan was estimated from the difference between the residual and initial protein concentration. Activity of chitosan-peroxidase conjugates was determined by the standard assay.

The purified peroxidase was entrapped on polyacrylamide and sodium alginate [35] and its potency to synthesize AgNPs was determined. Briefly, $5 \mathrm{ml}$ of acrylamide solution (30\%), dissolved in potassium phosphate buffer, $100 \mu \mathrm{l}$ of ammonium persulfate $(10 \%)$, mixed thoroughly with $1 \mathrm{ml}$ of peroxidase $(35.0 \mu \mathrm{mol} / \mathrm{mg})$ for $5 \mathrm{~min}$, then $50 \mu \mathrm{l}$ of TEMED was add. The gel was polymerized in casting cassette, uniformly cut into discs, washed by buffer. The activity polyacrylamide entrapped peroxidase was determined using $0.1 \mathrm{~g}$ of resin, incubated with the substrate solution, similar to the native enzyme assay.

For sodium alginate immobilization, $1 \mathrm{ml}$ of peroxidase $(35.0$ $\mu \mathrm{mol} / \mathrm{mg}$ ) was pipetted into $5 \mathrm{ml}$ of $1 \%$ sodium alginate in potassium phosphate buffer, mixed thoroughly, then dropped into $5 \mathrm{ml}$ of $1 \mathrm{M}$ $\mathrm{CalCl}_{2}$ with gentle stirring. The developed pellets were collected, washed and the activity of alginate immobilized peroxidase was determined, using $0.1 \mathrm{~g}$ of resin amended with the substrate solution, at standard assay conditions.

\section{Biochemical properties of the purified free and immobilized peroxidase}

The biochemical properties of the native and immobilized peroxidase were assessed. The optimum $\mathrm{pH}$ was studied using reaction mixture of different $\mathrm{pHs}$ with buffers potassium phosphate $(\mathrm{pH}$ 5.2-8.0) and Tris- $\mathrm{HCl}$ buffer $(\mathrm{pH} 8.0-10.2)$ at $50 \mathrm{mM}$. The activity of free peroxidase was assessed by the standard assay. The activity of immobilized enzyme was estimated using $0.1 \mathrm{~g}$ of the resin containing enzyme as chitosan, polyacrylamide and sodium alginate was supplemented with the $5 \mathrm{ml}$ of substrate solution at the same concentration, and the activity was measured by the standard assay. The $\mathrm{pH}$ stability of native and immobilized peroxidase was determined by pre-incubation of the enzymes at different $\mathrm{pH}$ range (5.8-10.2) for $2 \mathrm{~h}$ at $4^{\circ} \mathrm{C}$ then measuring their residual activity. The effect of reaction temperature on the peroxidases activity was determined by incubating the reaction mixture at different temperature $\left(30-50^{\circ} \mathrm{C}\right)$ and measuring the activity by standard assay.

\section{Results and Discussion}

\section{Potency of the isolated fungal isolates for AgNPs biosynthesis}

Fourteen fungal isolates were isolated from soils enriched with Ceramics Industrial Wastes. The fungal isolates were identified based on morphological features as Aspergillus niger, A. candidus, A. carneus, A. flavus, A. fumigatus, A. flavipes, A. terreus, A. oryzae, Penicillium citrinum, Cladosporiumsp, Microphomoniasp, Fusarium oxysporum, Cephalosporiummaydis and Sclerotium rolfsii. Among the fourteen isolates, only seven isolates (A. niger, A. candidus, A. flavus, A. fumigatus, A. terreus, $P$. citrinum, F. oxysporum) have the potentiality to reduce $\mathrm{Ag}^{+}$to $\mathrm{Ag}^{0}$ as revealed from the UV-Vis, TEM and DLS analyses as summarized in Table 1 . While, A carneus, A. flavipes, A. oryzae, Cladosporium sp., Microphomonia sp. and $S$. rolfsii lack the potentiality to synthesize $\mathrm{Ag}^{0}$ as revealed from the measured physical parameters. Five species of the genus Aspergillus namely; A. flavus, A. fumigatus, A. candidus, A. niger and $A$. terreus had the highest reducing potency to silver ions synthesizing AgNPs based on the visual color, UV-Vis and DLS analyses (Figure 1). The appearance of yellow-brown color suggesting the formation of AgNPs, the lack of precipitations or agglomeration assure the homogeneity and stability of developed AgNPs. Fungal extract without $\mathrm{AgNO}_{3}$ and sterile distilled water with $\mathrm{AgNO}_{3}$ as controls had no change in color of solution under the same conditions. From the UV-Vis analysis, the maximum absorption of the developed AgNPs by A. flavus, A. fumigatus, A. candidus, A. niger and $A$. terreus was centred at 436, 420, 430, 400 and $400 \mathrm{~nm}$, respectively. The absorption peak at $260-280 \mathrm{~nm}$ on the fungal extracts reveals the presence of DNA, proteins or aromatic amino acids that

\begin{tabular}{|c|c|c|c|c|c|}
\hline \multirow[t]{2}{*}{ No. } & \multirow[t]{2}{*}{ Fungal isolate } & \multirow{2}{*}{$\begin{array}{c}\text { Absorption peak }(\lambda \\
\mathrm{nm})\end{array}$} & \multirow[t]{2}{*}{ Zeta potential (mv) } & \multicolumn{2}{|c|}{ Size of AgNPs (nm) } \\
\hline & & & & DLS & TEM \\
\hline 1 & Aspergillus niger & 430 & - & 78 & - \\
\hline 2 & Aspergillus candidus & 400 & $-18.9,-39.9$ & 23 & $14-18$ \\
\hline 3 & Aspergillus carneus & - & - & - & - \\
\hline 4 & Aspergillus flavus & 436 & -30.4 & 9 & $6-13$ \\
\hline 5 & Aspergillus fumigatus & 420 & $-14.9,-38.9$ & 33 & $13-21$ \\
\hline 6 & Aspergillus flavipes & - & - & - & - \\
\hline 7 & Aspergillus terreus & 400 & $-8.7,18.9,30.4$ & 36 & $14-27$ \\
\hline 8 & Aspergillus oryzae & - & - & - & - \\
\hline 9 & Penicillium citrinum & 390 & - & 80 & $24-27$ \\
\hline 10 & Cladosporium sp. & - & - & - & - \\
\hline 11 & Microphomonia sp. & - & - & - & - \\
\hline 12 & Fusarium oxysporum & 430 & -29.2 & 11 & $13-19$ \\
\hline 13 & Cephalosporium maydis & - & - & - & - \\
\hline 14 & Sclerotium rolfsii & - & - & - & - \\
\hline
\end{tabular}

Table 1: Physical properties of AgNPs synthesized by various fungal isolates isolated from heavy metals contaminated samples. 
Citation: El-Sayed ASA, Rabie GH, El-Gazzar NS, Ali GS (2017) Immobilization and Characterization of Purified Aspergillus flavus Peroxidase Mediated Silver Nanoparticle Synthesis: Peroxidase Surface Reactive Residues are Implemented for Reduction of Silver lons, More than Its Active Sites. J Nanomed Nanotechnol 8: 420. doi: 10.4172/2157-7439.1000420

Page 4 of 8

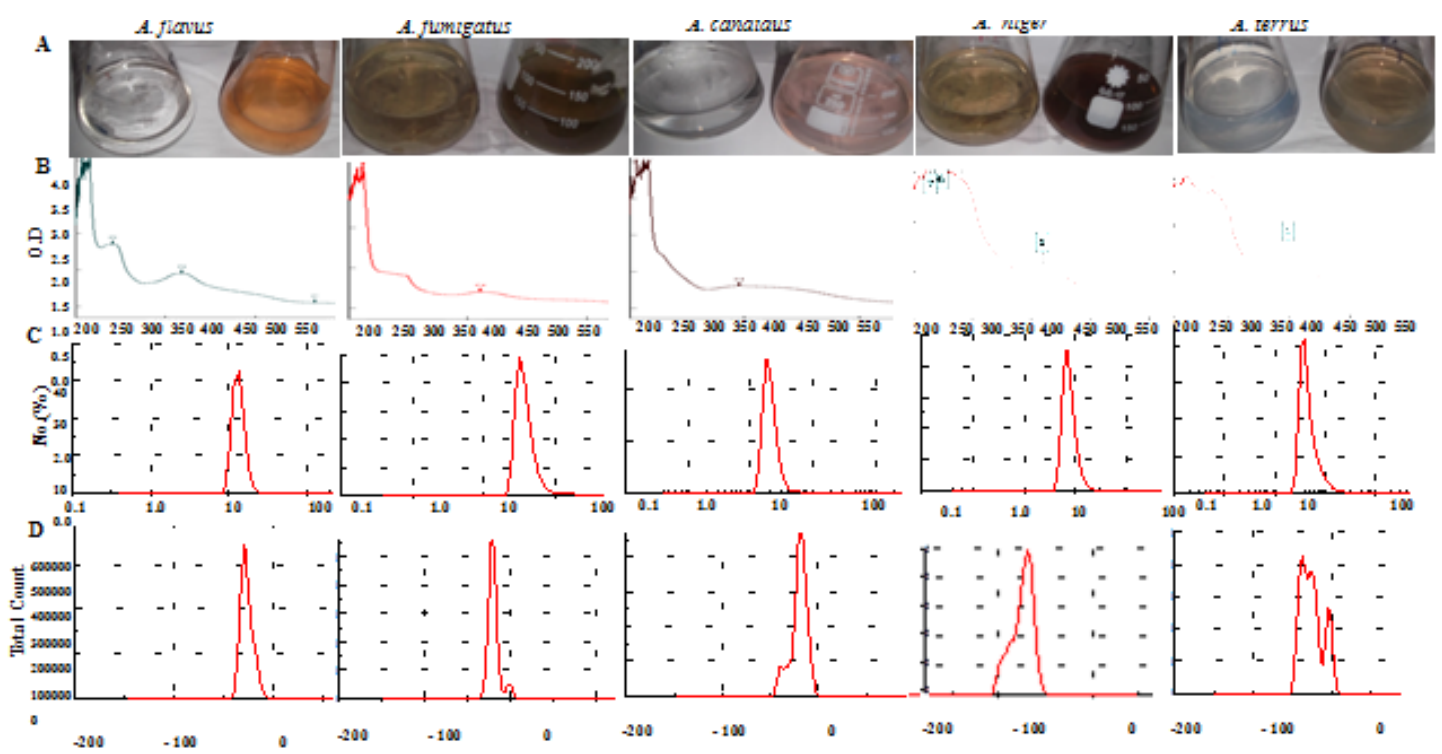

Figure 1: Biosynthesis of silver nanoparticles by the tested five species of Aspergillius (A. flavus, A. fungigatus, A. candidus and A. terreus). The fungi were grown for 5 days, the mycelial pellets were collected, washed and grinded in buffer containing PMSF and EDTA (protease inhibitors). The mycelium was amended with $1 \mathrm{mM} \mathrm{AgNO}_{3}$ for $10 \mathrm{hrs}$ then the visual appearance was photographed (A), UV-Vis analysis (B), Size analysis (C), and zeta potential (D).

involved in reduction of $\mathrm{Ag}^{+}$, stabilizing these particles [36]. The average hydrodynamic diameter and polydispersity indexes of the developed AgNPs for the experimented fungi was evaluated by DLS analysis (Figure 1C). The average diameter of AgNPs from A. flavus, A. fumigatus, A. candidus, A. niger and A. terreus was 9, 33, 23, 78 and $36 \mathrm{~nm}$, respectively. To assess the degree of stability of synthesized AgNPs, the charge was measured by Zeta potential. Zeta potential of AgNPs from A. flavus was $-30.4 \mathrm{mV}$ with one sharp peak, suggesting the higher stability of this NPs. Two zeta potential peaks of AgNPs from A. fumigatus $(-14.9 \mathrm{mV},-38.9 \mathrm{mV})$ and $A$. candidus $(-18.9 \mathrm{mV}$, $39.9 \mathrm{mV}$ ) were detected, while, AgNPs suspension from A. terreus had three major peaks at $-8.7,18.9$ and $30.4 \mathrm{mV}$. The higher negative charge of AgNPs as measured by zeta potential confirm the repulsion of the synthesized particles, subsequently led to stability and mono-dispersity of the synthesized AgNPs solution [37,38].

The size and shape of the synthesized AgNPs by the experimented fungi were determined from the TEM analysis (Figure 2). AgNPs from different fungal species had variable shapes that being depends on the identity of reducing agents and stabilizing compounds from each species, however, almost of the fungal synthesized AgNPs had spherical and triangular shapes. AgNPs diameter from A. flavus, A. fumigatus, A. candidus, A. terreus, and $A$. niger ranged from $6-13 \mathrm{~nm}, 13-21 \mathrm{~nm}, 14-18$ $\mathrm{nm}, 14-27 \mathrm{~nm}$ and 25-39 nm, respectively. Visually, AgNPs synthesized by $A$. flavus extracts was relatively stable till more than 25 days with no aggregations that might be due to the presence of stabilizing protein, in contrary to other Aspergilli which the color of AgNPs solution turned to deep brown, black due to the molecular aggregations. The colloidal stability of AgNPs synthesized by A. flavus extracts are consistent with those reported for other fungi [14] and Azospirillum [21]. To further validate the presence of stabilizing proteins, A. flavus extracts was analysed by FTIR, confirming the presence of various functional groups at $1643.2 \mathrm{~cm}^{-1}, 1604.7 \mathrm{~cm}^{-1}, 1801.4 \mathrm{~cm}^{-1}, 3994.5 \mathrm{~cm}^{-1}$, and 3201.6 $\mathrm{cm}^{-1}$ corresponding to carbonyl residues and peptide bonds of proteins (Figure $2 \mathrm{~F}$ ). The band at $1801.4 \mathrm{~cm}^{-1}$ referred to $\mathrm{C}=\mathrm{C}$ alkenyl group



Figure 2: Transmission Electron Microscope (TEM) image of silver nanoparticle synthesized by the crude intracellular extracts of $A$. flavus (A), A. fumigatus (B), A. candidius (C), A. terreus (D), and A. Niger (E).

stretch of protein in solution, whereas the bands at $1643.2 \mathrm{~cm}^{-1}$ and $1604.7 \mathrm{~cm}^{-1}$ are belonging to the amide I and II bonds. Similar results showing the presence of aldehyde and keto groups as stabilizing and capping agents to AgNPs synthesized from fungi [37,39]. The bands at $1643.2 \mathrm{~cm}^{-1}$ are belongs to carbonyl stretch of unsaturated aldehyde, ketone and alkene group, while the bands at $1604.7 \mathrm{~cm}^{-1}$ are belongs to $\mathrm{NH}_{2}$ stretch vibrations in the amide linkages of proteins. Consistently, AgNPs biosynthesis by filamentous fungi was extensively documented [40-42]. The strong fungal AgNPs productivity has been attributed to secretion of abundant extracellular redox proteins, diverse metal reductases, thus reducing soluble metal ions into their insoluble nanocrystals [43].

Thus, A. flavus was selected for further biochemical studies to elucidate its reducing potency which implemented for reduction of silver nitrate to AgNPs. 
Citation: El-Sayed ASA, Rabie GH, El-Gazzar NS, Ali GS (2017) Immobilization and Characterization of Purified Aspergillus flavus Peroxidase Mediated Silver Nanoparticle Synthesis: Peroxidase Surface Reactive Residues are Implemented for Reduction of Silver lons, More than Its Active Sites. J Nanomed Nanotechnol 8: 420. doi: 10.4172/2157-7439.1000420

\section{Biochemical identity of $A$. flavus metabolites implicated with synthesis of AgNPs}

To determine the coenzyme dependence of A. flavus reducing agents that implemented for AgNPs synthesis, various coenzymes as NADH and PLP were supplemented to fungal extracts and their potency to reduce $\mathrm{Ag}^{+}$was determined. Apparently, the reducing properties of $A$. flavus extracts to synthesize AgNPs was proportionally enhanced with $\mathrm{NADH}$ concentration $(0,1,5,10,50 \mathrm{mM})$ as revealed from visual appearance and UV-Vis analysis (Figure S1). Distilled water containing the same NADH concentrations was used as negative controls. At $50 \mathrm{mM} \mathrm{NADH}$, the synthesized AgNPs was increased by three folds comparing to zero NADPH. The significant reduction of $\mathrm{AgNO}_{3}$ to AgNPs with NADPH endorsing the implementation of $\mathrm{NADPH}$-dependent reductases for catalysing this reaction. However, incorporation of PLP to A. flavus extracts had no significant effect on enhancing AgNPs synthesis revealing the lack of participation of PLP-dependent enzymes on this process (Data not shown). To validate the hypothesis of NADH dependency of reductases on enhancement of AgNPs synthesis, the activity of NADH-dependent reductases particularly peroxidase and dehydrogenase were determined. In absence of NADPH, the activity of crude peroxidase and dehydrogenase were $8 \mu \mathrm{mol} / \mathrm{ml}$ and $2.7 \mu \mathrm{mol} / \mathrm{ml}$, respectively (Figure S1). However, the activity of peroxidase and dehydrogenase was increased by about 5 times at $50 \mathrm{mM}$ NADPH comparing to positive control. Consistently with these results, peroxidase was reported frequently as efficient reducing agents to $\mathrm{Ag}^{+}$to $\mathrm{AgNPs}[21,36,44]$. For the higher activity of peroxidase and statistically significant correlation with incorporation of NADH, we have been motivated to further purify and characterize this enzyme to synthesize AgNPs for more technological exploitations.

\section{Purification, molecular mass and AgNPs biosynthesis by $A$. flavus peroxidase}

NADPH-dependent peroxidase was purified from A. flavus extract by salting out and gel filtration chromatography, by the salting out (20$70 \%$ saturation), the activity of peroxidase was increased to $20 \mu \mathrm{mol} /$ $\mathrm{mg}$ comparing to $8 \mu \mathrm{mol} / \mathrm{mg}$ of the crude enzyme, i.e. purified by about 2.5 fold. By the gel filtration chromatography using Sephadex G100, followed by Sephadex G200, the specific activity of peroxidase was increased to $35 \mu \mathrm{mol} / \mathrm{mg}$, with 4.4 purification fold. The active fractions of peroxidase were gathered, concentrated by dialysis and its molecular homogeneity and subunit structure was analysed by SDSPAGE. The molecular mass of purified A. flavus peroxidase was $70 \mathrm{kDa}$ under SDS-PAGE, while its entire molecular mass was $140 \mathrm{kDa}$ under native-PAGE (Figure S2). Peroxidase from $A$. flavus has two identical subunits on their molecular mass, i.e. homodimer identity. From the Zymogram analysis, the activity of peroxidase was authenticated from the development of brown color due to the oxidation of substrate $O$-diansidine, allocating the enzyme on gel.

The potency of purified peroxidase to reduce $\mathrm{AgNO}_{3}$ for synthesis AgNPs was verified, two $\mathrm{ml}$ of the purified peroxidase $(35 \mu \mathrm{mol} / \mathrm{mg} /$ $\mathrm{ml}$ ) was amended with $1 \mathrm{mM} \mathrm{AgNO}_{3}$, incubated at $30^{\circ} \mathrm{C}$ for $1 \mathrm{~h}$. From the visual appearance, a greyish plasmon color was clearly developed revealing the synthesis of AgNPs in contrary to the colourless solution of control (Figure S2).

\section{Immobilization and biochemical properties of the free and immobilized peroxidase}

To evaluate the potency of peroxidase for bulk synthesis of AgNPs, the enzyme was immobilized on different solid supports such as chitosan, polyacrylamide and sodium alginate. Overall, the activity of purified A. flavus peroxidase was slightly reduced upon chemical conjugation. The activity of free peroxidase was $35.0 \mu \mathrm{mol} / \mathrm{mg}$, while the activity of enzyme conjugated with chitosan, sodium alginate and polyacrylamide was $24.3,23.2$ and $21.5 \mu \mathrm{mol} / \mathrm{mg}$, respectively. The yield of enzyme immobilization on chitosan, polyacrylamide and sodium alginate was $69.2,68.4$ and $66.2 \%$, respectively. Consistently, reduction of enzymes activity upon chemical conjugation was frequently reported [32]. Subsequently, to increase the yield of immobilization, different amino acids were used as active site protectants to block/mask the catalytic sites during the conjugation process [35]. Various amino acids such as lysine, arginine, cysteine and tyrosine as active sites containing residues of peroxidase [45] were incorporated into the enzyme solution at $100 \mathrm{mM}$, prior the immobilization process. Interestingly, lysine and arginine have an obvious effect on increasing the yield of peroxidase immobilization. Upon addition of lysine and arginine (separately), the yield of peroxidase immobilization was increased by $20 \%$ for chitosan, polyacrylamide and sodium alginate than the corresponding controls (Figure S2). Moreover, by using lysine and arginine together as active site protectants, the immobilization yield of peroxidase was dramatically increased by about $33 \%$ than corresponding controls. Thus, the specific activity of peroxidase immobilized on chitosan, polyacrylamide and sodium alginate was $31.2,30.5$ and $29.1 \mu \mathrm{mol} / \mathrm{mg}$, respectively, comparing to the free enzyme $(35 \mu \mathrm{mol} / \mathrm{mg})$.

To further evaluate the effect of chemical conjugation on the catalytic and structural properties of peroxidase, the biochemical properties of the free and immobilized enzyme was concurrently determined. The effect of medium $\mathrm{pH}$ on the activity of free and immobilized peroxidase was assessed. From the obtained results (Data not shown), the free and immobilized peroxidase have the same catalytic pattern in response to the reaction $\mathrm{pH}$ ranged from $\mathrm{pH}$ 5.8-10.2. The maximum activity of free and immobilized peroxidase was reported at reaction $\mathrm{pH} 7.5$, with significant reduction on their activities at higher acidic and alkaline $\mathrm{pHs}$. At reaction $\mathrm{pH} 4.2$ and $\mathrm{pH} 10.2$, the activity of free and immobilized peroxidases was reduced by about $40 \%$ comparing to control at $7.5 \mathrm{pH}$, suggesting the negligible effect of chemical modification by the current compounds on the ionic states of peroxidase. The $\mathrm{pH}$ stability of free and immobilized peroxidase was evaluated at $\mathrm{pH}$ range from 6.0-9.0. The highest stability of free and immobilized peroxidase was detected at $\mathrm{pH}$ range 7.4-7.8, with an obvious decreasing to the enzymes activities by about $55 \%$ at $\mathrm{pH} 6.0$ and 9.0 , comparing to control. The significant reduction of the enzymes activities at $\mathrm{pH} 6.0$ and 9.0, might be due to the enzyme denaturing or changing the ionic state of the enzymes thus masking the proper interaction with their substrates. The current approaches of peroxidase modification have no significant effect on the kinetics of catalysis and structure of peroxidase.

The effect of reaction temperature $\left(30-50^{\circ} \mathrm{C}\right)$ on activity of the free and immobilized peroxidase was evaluated. The maximum activity of the free and immobilized peroxidase was recorded at reaction temperature $35^{\circ} \mathrm{C}$ and $40^{\circ} \mathrm{C}$, with obvious decreasing to the enzymes activities at higher temperature $\left(50^{\circ} \mathrm{C}\right)$. At $40^{\circ} \mathrm{C}$, the activity of peroxidase immobilized on chitosan, polyacrylamide and sodium alginate was increased to $34.0,32.3$ and $30.9 \mu \mathrm{mol} / \mathrm{mg}$, respectively, i.e. by about $6.0 \%-9.0 \%$ more than control (at $35^{\circ} \mathrm{C}$ ). However, the activity of peroxidases was dramatically decreased by $55 \%$ by incubation at $50^{\circ} \mathrm{C}$, suggesting the enzyme denaturation. The slight increasing on optimum reaction temperature for immobilized peroxidase over the free enzyme seems to be reasonable due to increasing the diffusion of substrate influx and product efflux during catalysis process [32]. The thermal stability of free and immobilized peroxidase was evaluated by 
Citation: El-Sayed ASA, Rabie GH, El-Gazzar NS, Ali GS (2017) Immobilization and Characterization of Purified Aspergillus flavus Peroxidase Mediated Silver Nanoparticle Synthesis: Peroxidase Surface Reactive Residues are Implemented for Reduction of Silver lons, More than Its Active Sites. J Nanomed Nanotechnol 8: 420. doi: 10.4172/2157-7439.1000420

pre-incubation of the enzymes at different temperature then measuring their residual activity. From the kinetics of thermal stability (Table 2), the immobilized peroxidase exhibited a higher thermal structural stability comparing to free peroxidase. At $40^{\circ} \mathrm{C}$, the half-life time $\left(T_{1 / 2}\right)$ of peroxidase immobilized on chitosan, polyacrylamide and sodium alginate was 3.6, 7.8 and $7.8 \mathrm{~h}$, respectively, while it was $2.7 \mathrm{~h}$ for the free enzyme. At $40^{\circ} \mathrm{C}$, the enzyme structural stability was increased by 1.4, 2.9 and 2.9 fold upon conjugation with chitosan, polyacrylamide and sodium alginate, respectively. Immobilization has a dramatically positive effect on catalytic and structural stabilities of peroxidase against thermal denaturing as revealed from thermal treatment at $60^{\circ} \mathrm{C}$. The structural stability of peroxidase conjugated with chitosan, polyacrylamide and sodium alginate was increased by $33.6 \%, 40.2 \%$ and $35.0 \%$, respectively, normalizing to the free enzyme at $70^{\circ} \mathrm{C}$. The half-life temperature $\left(T_{m}\right)$ of the chemically conjugated peroxidase was $2.8-3.2 \mathrm{~h}$ comparing to $2.4 \mathrm{~h}$ to free peroxidase. In addition, the thermal inactivation rate $\left(K_{r}\right)$ of peroxidase was dramatically reduced by chemical conjugation than the free enzyme. From the thermal kinetic properties of the free and immobilized enzyme, the current chemical modification approaches strongly stabilize the structural and catalytic properties of enzymes as consistent with those reported for other enzymes [32].

\section{AgNPs synthesis and operative stability of the free and immobilized peroxidase}

The actual potency of free and immobilized peroxidase to reduce silver ions to AgNPs was investigated. Five $\mathrm{ml}$ of free and immobilized peroxidase (at the same concentration $6.0 \mu \mathrm{mol} / \mathrm{mg}$ ) in $15 \mathrm{ml}$ tubes were amended with $1 \mathrm{mM} \mathrm{AgNO}$ incubated for $2 \mathrm{~h}$ at $40^{\circ} \mathrm{C}$ with gentle stirring. The synthesis of AgNPs was visually monitored from the development of yellow color comparing to control. The reaction mixture was withdrawn, the developed AgNPs was centrifuged, washed and re-suspended in distilled water. The concentration and size of AgNPs were measured by UV-Vis, DLS and TEM analyses. The size of developed AgNPs from the activity of immobilized peroxidase on chitosan, polyacrylamide and sodium alginate was ranged from 13-16 $\mathrm{nm}, 16-22 \mathrm{~nm}$ and $25-39 \mathrm{~nm}$, respectively, while it was $15-30 \mathrm{~nm}$ for the free enzyme. From the DLS analysis, the size of AgNPs synthesized by native peroxidase and immobilized on chitosan, polyacrylamide and sodium alginate was around $80 \mathrm{~nm}$ (Figure 3).

\begin{tabular}{|c|c|c|c|c|}
\hline Enzyme & Temp. $\left({ }^{\circ} \mathrm{C}\right)$ & $\mathrm{T}_{1 / 2}(\mathrm{hr})$ & SF (\%) & $\operatorname{Tm}\left({ }^{\circ} \mathrm{C}\right)$ \\
\hline \multirow{4}{*}{ Free Peroxidase } & 40 & 5.31 & 100 & \multirow{4}{*}{54} \\
\hline & 50 & 2.7 & 100 & \\
\hline & 60 & 2.38 & 100 & \\
\hline & 70 & 1.94 & 100 & \\
\hline \multirow{4}{*}{ Chitosan-peroxidase } & 30 & 9.01 & 169.7 & \multirow{4}{*}{62} \\
\hline & 40 & 3.57 & 132.3 & \\
\hline & 50 & 2 & 84.03 & \\
\hline & 60 & 1.86 & 95.9 & \\
\hline \multirow{4}{*}{$\begin{array}{l}\text { Sodium- alginate } \\
\text { Peroxidase }\end{array}$} & 30 & 6.77 & 127.5 & \multirow{4}{*}{68.7} \\
\hline & 40 & 7.78 & 288.1 & \\
\hline & 50 & 2.37 & 100 & \\
\hline & 60 & 3 & 154.6 & \\
\hline \multirow{4}{*}{$\begin{array}{l}\text { Polyacrylamide- } \\
\text { peroxidase }\end{array}$} & 30 & 6.6 & 127.5 & \multirow{4}{*}{66.6} \\
\hline & 40 & 7.7 & 285.1 & \\
\hline & 50 & 2.4 & 100.84 & \\
\hline & 60 & 3 & 154.6 & \\
\hline
\end{tabular}

Table 2: Thermal stability kinetic parameters of the purified peroxidase immobilized on chitosan, sodium alginate and polyacrylamide.
The operative stability of immobilized peroxidase for continuous reduction of $\mathrm{Ag}^{+}$was assessed. The pellets of peroxidase immobilized on various resins was washed, supplemented with $1 \mathrm{mM} \mathrm{AgNO}$ incubated under the standard conditions, their catalytic stability for mass production of AgNPs was evaluated via five successive reaction cycles. The physical properties of synthesized AgNPs were assessed for each cycle. For the free peroxidase, the developed AgNPs have maximum absorption at $\mathrm{A}_{390} \mathrm{~nm}$, with the actual size $70-81.0 \mathrm{~nm}$ by DLS analysis, while from the TEM micrographs the AgNPs appears spherical, oval shaped with size ranged from $15-30 \mathrm{~nm}$ (Figure 3). From the operative stability, the immobilized peroxidase has the potency for synthesis of AgNPs till the $5^{\text {th }}$ catalytic cycle. Due to the presence of free reactive aldehyde groups that might participates in reduction of $\mathrm{Ag}^{+}$to $\mathrm{Ag}^{0}$ [46], blanks of chitosan, polyacrylamide and sodium alginate were used. By the $3^{\text {rd }}$ catalytic cycle, the reductive potency of immobilized peroxidase to $\mathrm{Ag}^{+}$was reduced by about $50 \%$, and reduced by about $70 \%$ by the $5^{\text {th }}$ catalytic cycle, normalizing to the first cycle. The AgNPs concentration for each cycle was calculated from the intensity of absorption at 390-420 nm. For the immobilized peroxidases, the yield of synthesized AgNPs was decreased sequentially with the reaction cycling, that could be due to the release of enzyme during washing or even enzyme denaturing. Practically, the immobilized peroxidase being economically more feasible than free enzyme that it can be used for bulk production of AgNPs for at least three catalytic cycles, thus, producing AgNPs by three times more than the free enzyme. However, we had assumed that part of the synthesized AgNPs was adsorbed to the surface of chitosan, or entrapped to the polyacrylamide or sodium

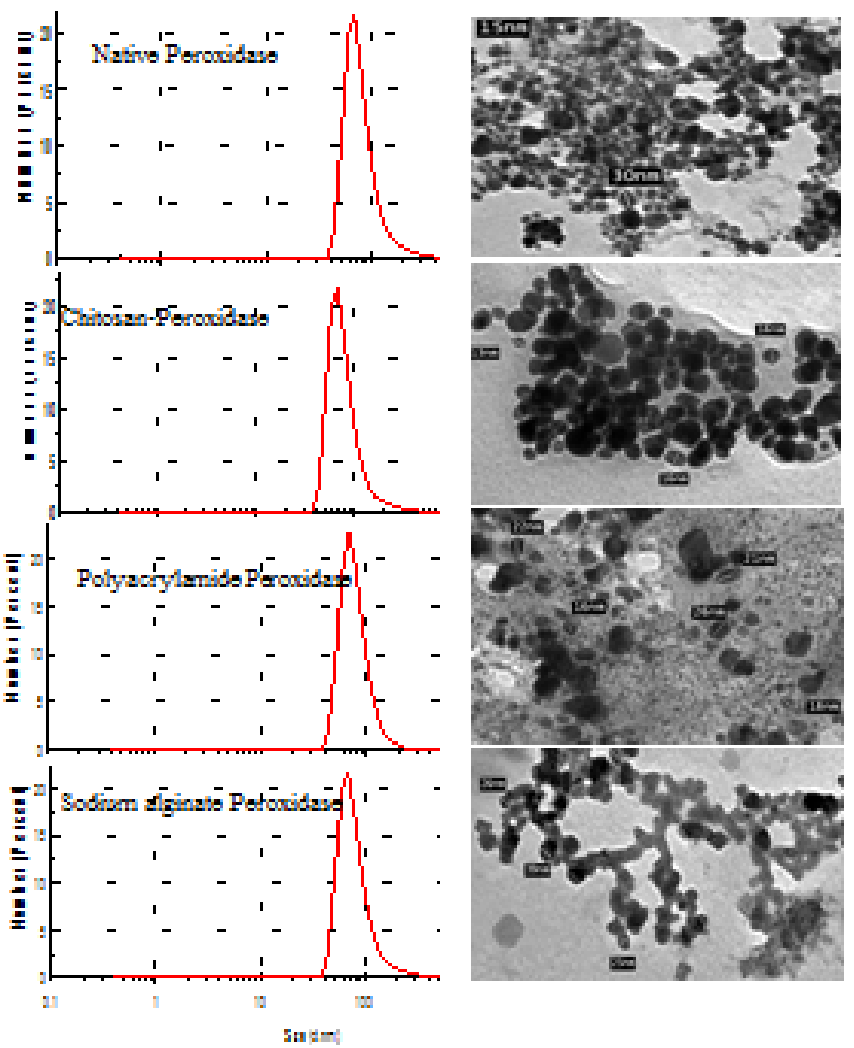

Figure 3: DLS and TEM micrographs of the synthesized AgNPs by the free and immobilized peroxidase. The size of AgNPs synthesized by free and immobilized peroxidase by DLS analysis (Right panel), and morphology and size of AgNPs by TEM analysis (Left panel). 
Citation: El-Sayed ASA, Rabie GH, El-Gazzar NS, Ali GS (2017) Immobilization and Characterization of Purified Aspergillus flavus Peroxidase Mediated Silver Nanoparticle Synthesis: Peroxidase Surface Reactive Residues are Implemented for Reduction of Silver lons, More than Its Active Sites. J Nanomed Nanotechnol 8: 420. doi: 10.4172/2157-7439.1000420

alginate resins. To validate this hypothesis, after the $2^{\text {nd }}$ reaction cycle, the pellets of chitosan immobilized peroxidase were washed thoroughly by sterile distilled water and analysed by TEM. The TEM micrographs (Figure S3) ensure the presence of AgNPs adsorbed to the surface of chitosan pellets. Thus, in spite of applicable feasibility of immobilized peroxidase as a new technology for $\mathrm{Ag}^{0}$ biosynthesis, adsorption of $\mathrm{Ag}^{0}$ to the surface of chitosan pellets is one of raised technical arguments.

Implementation of surface thiols or surface reactive amino groups of enzymes on reduction of silver ions to AgNPs, is one of the technical arguments. To understand the identity of reducing agents to $\mathrm{Ag}^{+}$, the native enzyme was denatured by autoclaving for $30 \mathrm{~min}$, then amended with silver nitrate solution at $1 \mathrm{mM}$, incubated under authentic conditions and the development of AgNPs was visually monitored (Figure S3). Strikingly, the autoclaved and non-autoclaved (control) peroxidase have the same reducing effect of silver ions to AgNPs, that implies the surface thiols or amino groups or aldehydes of amino acids act as reducing agents of silver ions to AgNPs in addition to its stabilization. Thus, reduction of $\mathrm{Ag}^{+}$to $\mathrm{Ag}^{0}$ is mainly due to surface reactive groups of peroxidase as protein but does not to its functionality as enzyme. Similar results reporting the responsibility of surface free amino groups, cysteine residues and carboxyl groups on electrostatic interaction with $\mathrm{Ag}^{+}$ions to form $\mathrm{Ag}^{0}$ [12]. Consistently, several enzymes such as glucosidase [16], trypsin [17], pepsin [47], laccase [18], lysozyme, and fibrinolytic enzymes [48] were used as reducing peptides for nanoparticles synthesis due to their reactive amino acids, but not for their functionality as enzymes. Amino acids as phenylalanine, tyrosine, tryptophan, cysteine, histidine, and lysine are the major amino acids depicted for reduction of ions to the corresponding nanoparticles and their stabilization [20].

\section{Conclusion}

The potency of Aspergillus flavus for reduction of silver ions to its nanoparticles has been emphasized in terms of size, quantity and morphology. The identity of silver ions reducing agents from $A$. flavus was disclosed as NADPH-dependent reductases, peroxidase. Peroxidase was purified from A. flavus and immobilized into solid support and biochemically characterized. To the best of knowledge, this is first report emphasize the operative stability of immobilized peroxidase for synthesis of AgNPs on industrial scale for various technological exploitations.

\section{Acknowledgements}

This work was supported by Botany and Microbiology Department, Faculty of Science, Zagazig University, Egypt.

\section{References}

1. Prabhu S, Poulose EK (2012) Silver nanoparticles: mechanism of antimicrobial action, synthesis, medical applications, and toxicity effects. International Nano Letters 2: 1-10.

2. Gaffet E, Tachikart M, El Kedim O, Rahouadj R (1996) Nanostructural materials formation by mechanical alloying: Morphologic analysis based on transmission and scanning electron microscopic observations. Materials Characterization 36: $185-190$

3. Salkar RA, Jeevanandam P, Aruna ST, Koltypin Y, Gedanken A (1999) The sonochemical preparation of amorphous silver nanoparticles. Journal of materials chemistry 9: 1333-1335

4. Mandal S, ArumugamRenu SK, Pasricha R, Sastry M (2005) Silver nanoparticles of variable morphology synthesized in aqueous foams as novel templates. Bulletin of Materials Science 28: 503-510.

5. Jiang H, Moon K, Zhang Z, Pothukuchi S, Wong Email CP (2006) Variable Frequency Microwave Synthesis of Silver Nanoparticles. Journal of Nanoparticle Research 8: 117-124.
6. Sun YP, Atorngitjawat P, Meziani MJ (2001) Preparation of silver nanoparticles via rapid expansion of water in carbon dioxide microemulsion into reductant solution. Langmuir 17: $5707-5710$.

7. Tien DC, Tseng KH, Liao CY, Tsung TT (2008) Colloidal silver fabrication using the spark discharge system and its antimicrobial effect on Staphylococcus aureus. Medical engineering and physics 30: 948-952.

8. Remya N, Hanna VS, Nair BJ, Maekawa T, Yoshida Y, et al. (2010) Nanoparticulate material delivery to plants. Plant science 179: 154-163.

9. Orafai H, Kallinteri P, Garnett M, Huggins S, Hutcheon G, et al. (2010) Novel poly (glycerol-adipate) polymers used for nanoparticle making: a study of surface free energy. Iranian Journal of Pharmaceutical Research 7: 11-19.

10. Korbekandi H, Iravani S, Abbasi S (2009) Production of nanoparticles using organisms. Critical Reviews in Biotechnology 29: 279-306.

11. Iravani S (2011) Green synthesis of metal nanoparticles using plants. Green Chemistry 13: 2638-2650.

12. Mukherjee P, Ahmad A, Mandal D, Senapati S, Sainkar SR, et al. (2011) Bioreduction of AuCl4-ions by the fungus, Verticillium $\mathrm{sp}$. and surface trapping of the gold nanoparticles formed. Angewandte Chemie International 40: 35853588

13. Lacerda ICA, de Castro HF, Dias MA, Pimentel PF, Rosa CA, et al. (2002) Removal of heavy metals by an Aspergillus terreus strain immobilized in polyurethane matrix. Letters in applied microbiology 34: 46-50.

14. Absar A, Priyabrata M, Satyajyoti S, Deendayal M, Khan I, et al. (2003) Extracellular biosynthesis of silver nanoparticles using the fungus Fusarium oxysporum. Colloids and surfaces B: Biointerfaces 28: 313-318.

15. Xie J, Lee JY, Daniel IC, Ting YP (2007) High-Yield Synthesis of Complex Gold Nanostructures in a Fungal System. The Journal of Physical Chemistry C 111 : 16858-16865.

16. Govindaraju K, Kiruthiga V, Manikandan R, Ashokkumar T, Singaravelu G, et al. (2011) $\beta$-glucosidase assisted biosynthesis of gold nanoparticles: A green chemistry approach. Materials Letters 65: 256-259.

17. Li L, Weng J (2010) Enzymatic synthesis of gold nanoflowers with trypsin. Nanotechnology 21: 305603

18. Faramarzi MA, Forootanfar H (2011) Forootanfar, Biosynthesis and characterization of gold nanoparticles produced by laccase from Paraconiothyrium variabile. Colloids and Surfaces B: Biointerfaces 87: 23-27.

19. Rangnekar A, Sarma TK, Singh AK, Deka J, Ramesh A, et al. (2007) Retention of enzymatic activity of $\alpha$-amylase in the reductive synthesis of gold nanoparticles. Langmuir 23: 5700-5706.

20. Das R, Jagannathan R, Sharan C, Kumar U, Poddar P, et al. (2009) Mechanistic study of surface functionalization of enzyme lysozyme synthesized Ag and Au nanoparticles using surface enhanced Raman spectroscopy. The Journal of Physical Chemistry C 113: 21493-21500.

21. Kupryashina M, Vetchinkina E, Nikitina V (2016) Biosynthesis of silve nanoparticles with the participation of extracellular $\mathrm{Mn}$-dependent peroxidase from Azospirillum. Applied Biochemistry and Microbiology 52: 384-388.

22. Raper KB, Fennell DI (1965) The genus Aspergillus. Science.

23. Domsch KH, Gams W, Anderson TH (2007) Compendium of soil fungi. (2 Edtn), Academic Press Ltd, London.

24. de Santi M, Sisti M, Barbieri E, Piccoli G, Brandi G, et al. (2010) A combined morphologic and molecular approach for characterizing fungal microflora from a traditional Italian cheese (Fossa cheese). International dairy journal 20: 465-471.

25. El-Sayed AS, Khalaf SA, Aziz HA (2013) Characterization of homocysteine $\mathrm{Y}$-lyase from submerged and solid cultures of Aspergillus fumigatus ASH (JX006238). Journal of microbiology and biotechnology 23: 499-510.

26. El-Sayed AS, Shindia AA, Zaher YA (2013) Purification and characterization of L-amino acid oxidase from the solid-state grown cultures of Aspergillus oryzae ASH. Microbiology 82: 762-771.

27. Claiborne AL, Fridovich I (1979) Chemical and enzymic intermediates in the peroxidation of o-dianisidine by horseradish peroxidase. 1 . Spectral properties of the products of dianisidine oxidation. Biochemistry 18: 2324-2329.

28. Decker LA (1977) Worthington enzyme manual. Worthington Biochemical corporatrion. 
Citation: El-Sayed ASA, Rabie GH, El-Gazzar NS, Ali GS (2017) Immobilization and Characterization of Purified Aspergillus flavus Peroxidase Mediated Silver Nanoparticle Synthesis: Peroxidase Surface Reactive Residues are Implemented for Reduction of Silver lons, More than Its Active Sites. J Nanomed Nanotechnol 8: 420. doi: 10.4172/2157-7439.1000420

29. Bradford MM (1979) A rapid and sensitive method for the quantitation of microgram quantities of protein utilizing the principle of protein-dye binding. Analytical biochemistry $72: 248-254$

30. El-Sayed ASA (2011) Purification and characterization of a new L-methioninase from solid cultures of Aspergillus flavipes. The Journal of Microbiology 49: 130-140.

31. El-Sayed ASA, Shindia AA, Zaher Y (2012) L-Amino acid oxidase from filamentous fungi: screening and optimization. Annals of Microbiology 62: 773-784

32. El-Sayed ASA, Hassan MN, Nada H (2015) Purification, immobilization and biochemical characterization of I-arginine deiminase from thermophilic Aspergillus fumigatus KJ434941: Anticancer activity in vitro. Biotechnology progress 31: 396-405.

33. Laemmli UK (1970) Cleavage of structural proteins during the assembly of the head of bacteriophage T4. Nature 227: 680-685.

34. Wayne LG, Diaz GA (1986) A double staining method for differentiating between two classes of mycobacterial catalase in polyacrylamide electrophoresis gels. Analytical Biochemistry 157: 89-92.

35. El-Sayed A, Shindia A (2011) Characterization and immobilization of purified Aspergillus flavipesl-methioninase: continuous production of methanethiol. Journal of applied microbiology 111: 54-69.

36. Welinder KG (1979) Amino Acid Sequence Studies of Horseradish Peroxidase. European Journal of Biochemistry 96: 495-502.

37. Durán N, Marcato PD, Alves OL, De Souza GIH, Esposito E, et al. (2005) Mechanistic aspects of biosynthesis of silver nanoparticles by several Fusarium oxysporum strains. Journal of nanobiotechnology 3: 1.

38. Shaligram NS, Bule M, Bhambure R, Singhal RS, Singh SK, et al. (2009) Biosynthesis of silver nanoparticles using aqueous extract from the compactin producing fungal strain. Process biochemistry 44: 939-943.

39. Moteshafi H, Mousavi S, Shojaosadati S (2012) the possible mechanisms involved in nanoparticles biosynthesis. Journal of Industrial and Engineering Chemistry 18: 2046-2050.
40. Fayaz AM, Balaji K, Girilal M, Yadav R, Kalaichelvan PT, et al. (2010) Biogenic synthesis of silver nanoparticles and their synergistic effect with antibiotics: a study against gram-positive and gram-negative bacteria. Nanomedicine: Nanotechnology, Biology and Medicine. 6: 103-109.

41. Bhainsa KC, S. D'souza SF (2006) Extracellular biosynthesis of silver nanoparticles using the fungus Aspergillus fumigatus. Colloids and surfaces $B$ Biointerfaces 47: 160-164.

42. Zhang X, Yan S, Tyagi RD, Surampalli RY (2011) Synthesis of nanoparticles by microorganisms and their application in enhancing microbiological reaction rates. Chemosphere 82: 489-494

43. Balaji DS, Basavaraja S, Deshpande R, Mahesh DB, Prabhakar BK, et al. (2009) Extracellular biosynthesis of functionalized silver nanoparticles by strains of Cladosporium cladosporioides fungus. Colloids and surfaces B: biointerfaces 68: 88-92.

44. Cicek S, Gungor AA, Adiguzel A, Nadaroglu H (2015) Biochemical Evaluation and Green Synthesis of Nano Silver Using Peroxidase from Euphorbia (Euphorbia amygdaloides) and Its Antibacterial Activity. Journal of Chemistry.

45. Armon A, Graur D, Ben-Tal N (2001) ConSurf: an algorithmic tool for the identification of functional regions in proteins by surface mapping of phylogenetic information. Journal of molecular biology 307: 447-463.

46. Mishra A, Singh P, Sardar M (2015) Peroxidase assisted biosynthesis of silver and gold nanoparticles: Characterization and computational study. Adv Mater Lett 6: 194-200.

47. Kawasaki H, Hamaguchi K, Osaka I, Arakawa R (2011) ph-Dependent Synthesis of Pepsin-Mediated Gold Nanoclusters with Blue Green and Red Fluorescent Emission. Advanced Functional Materials 21: 3508-3515.

48. Deepak V, Umamaheshwaran PS, Guhan K, Nanthini RA, Krithiga B, et al. (2011) Synthesis of gold and silver nanoparticles using purified URAK. Colloids and Surfaces B: Biointerfaces 86: 353-358. 